
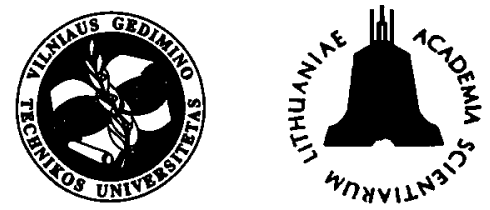

JOURNAL OF CIVIL ENGINEERING AND MANAGEMENT

http:/www.vtu.lt/english/editions

2003, Vol IX, No 3, 163-171

\title{
DAMAGE OF HIGH-STRENGTH REINFORCED CONCRETE COLUMNS UNDER HORIZONTAL AND VERTICAL LOADING
}

\author{
Rogerio Bairrăo ${ }^{1}$, Rimantas Kačianauskas ${ }^{2}$, Romualdas Kliukas ${ }^{3}$ \\ ${ }^{1}$ National Laboratory for Civil Engineering, Portugal. E-mail: bairao@lnec.pt \\ ${ }^{2,3}$ Dept of Materials Strength, Vilnius Gediminas Technical University, \\ Sauletekio al. 11, LT-2040 Vilnius, Lithuania \\ 2E-mail: rkac@fm.vtu.lt3E-mail:romkliu@fm.vtu.lt
}

Received 13 March 2003; accepted 23 May 2003

\begin{abstract}
The global damage of the high-strength reinforced concrete columns is investigated experimentally. Two identical specimens with annular cross-section and spiral containment were designed and two tests up to failure for the both specimens were carried out at the LNEC shaking table facilities. The columns worked as plane cantilever beams under the action of the constant vertical concentrated force and time-dependent concentrated horizontal force. The global damage concept is based on stiffness degradation. A variation of the observed horizontal displacements and forces during experiments as well as evolution of damage are presented and considered in details. The results show that increase of loading values is dominating factor of the global damage.
\end{abstract}

Keywords: high-strength reinforced concrete, column specimen, shaking table, global damage.

\section{Introduction}

The design of reliable high-quality engineering structures requires understanding the mechanical behaviour of smaller members and the accumulation of damage up to failure. The high-strength concrete specimens of hollow circular cross-section with longitudinal and spiral reinforcement investigated here may be considered as members of complex structures used in many fields of engineering.

The accumulation of damage in reinforced concrete structures is a process lasting during the whole period of operation until the critical state (failure) of the structure is reached. During the evolution of damage the macroscopic properties of the material, or the entire structure, change because of the nucleation and the growth of cracks. Therefore geometry, reinforcement, manufacturing and other factors may be of major importance concerning irreversible changes.

In spite of the above complexity, the existing variety of damage models is essentially of a phenomenological nature. The concept of damage was probably first introduced by Kachanov [1]. Nowadays, even the definition of damage variables is non-unique. Damage, generally speaking, can be interpreted as a decay of mechanical properties with increasing stress and/or strain [2]. Many of the models proposed to describe the static or cyclic behaviour of concrete are based on damage mechanics also coupled with plasticity [3-4] but the dam- age of high-strength concrete usually remains linear and elastic [5]. Most of the quoted models are capable to describe the behaviour of concrete under loading histories involving multiaxial loads by macroscale models. The elastic nature character of high-strength concrete damage is observed by investigation of material properties [6].

In spite of the existence of damage models to evaluate the actual behaviour of high-strength concrete structures, experimental testing still remains the most powerful and reliable research tool. The main reason for large scale testing is that the actual behaviour of materials depends on the specimens scale. It must be stated, however, that experimental research is progressing at a much lower rate than the theoretical one. The lack of experimental data is a serious drawback in the reliability evaluation of the proposed theoretical models, when applied to structural members.

Many investigations concerning experimental research on the high-strength concrete as material and high-strength concrete columns with annular section may be found in references [6-12].

The tests of structural members submitted to combined longitudinal and transverse loading, especially under cyclic loading, belong to the category of the most complicated experiments. The advanced and innovative shaking table testing techniques used in the present investigation started its development in the early fifties. It remains as an essential tool in dynamic experimentation and provides a base for realistic simulation as it allows the study of true inertia forces acting on the specimens. 
Several shaking tables throughout the European Union [13] as well as in the USA [14] and Japan [15] are being used to develop research activities concerning the dynamic effects on civil engineering structures. An advanced triaxial shaking table was also designed and built in the Portuguese National Laboratory for Civil Engineering (LNEC) [16-18]. It consists of a large rectangular platform (or table) that can be driven in up to six degrees of freedom, where test specimens are fixed to the platform and subjected to a well defined dynamic input.

The current experimental investigation of highstrength reinforced concrete columns under horizontal and vertical loading was carried out by the LNEC shaking table facilities. The column works as a plane cantilever beam under the action of a constant vertical and timedependent concentrated horizontal force. The technical data of the experiments may be found in [19], while the global idea of the testing procedure and some of the measured and processed results are already presented in [20-22].

The present paper is mainly focussed on the presentation of results describing the global behaviour and the damage evolution of the specimens. A variation of the observed horizontal displacements and forces during the tests, as well as force-displacement diagrams, are presented. Finally, evolution of damage based on a stiffness degradation concept is considered in detail.

\section{Description of experiment and basic data}

Two identical reinforced concrete specimens V1 and V2 with annular cross-section and spiral containment were designed and two tests up to failure, separated into six stages denoted as $S 1$ until $S 6$ for the both specimens, were carried out. The entire specimens were produced as monolithic units consisting of a massive footing and a specified column. The columns have been erected using high-strength concrete with about $f_{c}=80 \mathrm{MPa}$. They have a wall thickness of $6 \mathrm{~cm}$. Longitudinal reinforcement consisted of 8 bars of $10 \mathrm{~mm}$ diameter and transverse reinforcement was a spiral made up with $6 \mathrm{~mm}$ diameter bars spaced $5 \mathrm{~cm}$ at the critical section. The mechanical properties of the concrete used for the columns as well as for the lower strength footing were evaluated by standard compression tests, performed by a series of cubic and cylindrical probes.

The tested columns were considered as vertical cantilever beams loaded by combined vertical and horizontal actions (Fig 1). A vertical load of $N=187,5 \mathrm{kN}$, producing the axial force, was applied before the tests and remained constant during the entire testing period. It was implemented by prestressing a cable positioned inside the column, at its centre line, and connected from the top of the column to a hollow zone under the footing. The presence of vertical load reduces the effect of damage in handling and increase the correspondence between experiment and service.

The horizontal time-dependent loading was produced by the motion of the shaking table and by an inertia mass involving a set of external additional masses and a connecting rod. The total value of this mass was $m=12 \mathrm{t}$. The motion of the shaking table was prescribed as a function of the transverse horizontal time-dependent displacement. For these experiments, sine type signals, controlled in amplitude and frequency, were used.

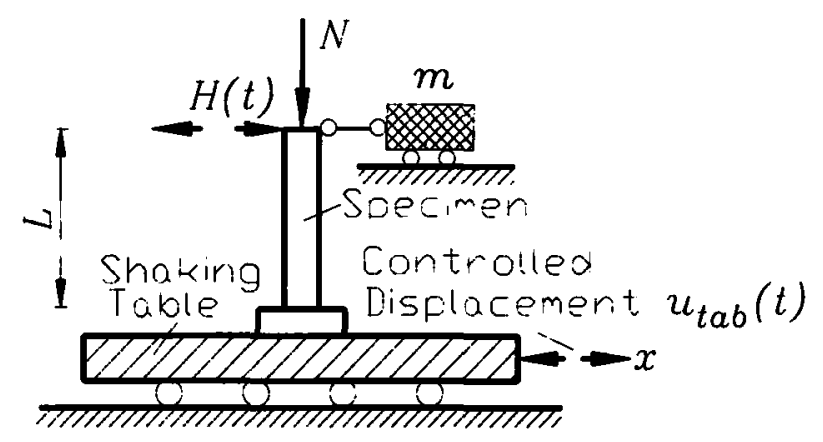

Fig 1. Schematic illustration of testing

During these tests the movement of the shaking table was imposed along its transverse direction and 21 channels were acquired. Optical transducers were used to measure the displacements at preselected points of the specimens. The positions of these displacement transducers, measuring the transverse displacements used in the current presentation, are shown in Fig 2. Transducer d11 was used to measure the transverse (in plane) displacement of the column top, while transducer d13 has measured the imposed transverse displacements of the shaking table itself.

Any eventual sliding of the footings on the shaking table was measured by the inductive transducer $\mathrm{dl}$. The horizontal force $H(t)$, generated at the top of the column, was measured by a loading cell, inserted as part of the connecting rod between the specimens and the inertial mass.

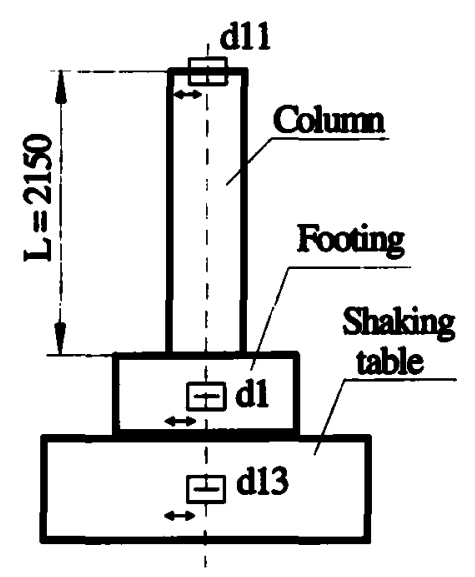

Fig 2. Location of the displacement transducers 
Bairrao et al [19-22] have already described the details of the specimen and testing procedure.

\section{Illustration of experimental results}

The main goal of these tests was to investigate the global behaviour of the specimen during the cyclic loading. The experimentally obtained maximum ductility of the structure described by the force-displacement diagram was regarded as an indicator of the global damage. The illustration of experimental results presented below presents the relative transverse time-dependent displacement $u(t)$ of the top of specimen with respect to the footing and the time-dependent horizontal force $H(t)$.
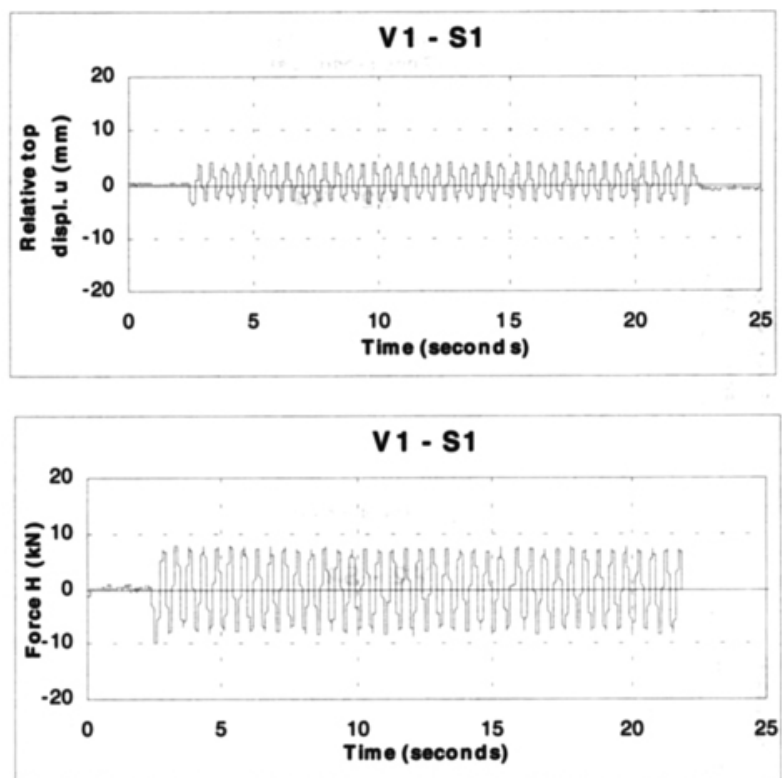

Fig 3. Variation of displacement $u$ ant load $H$ in the stage S1
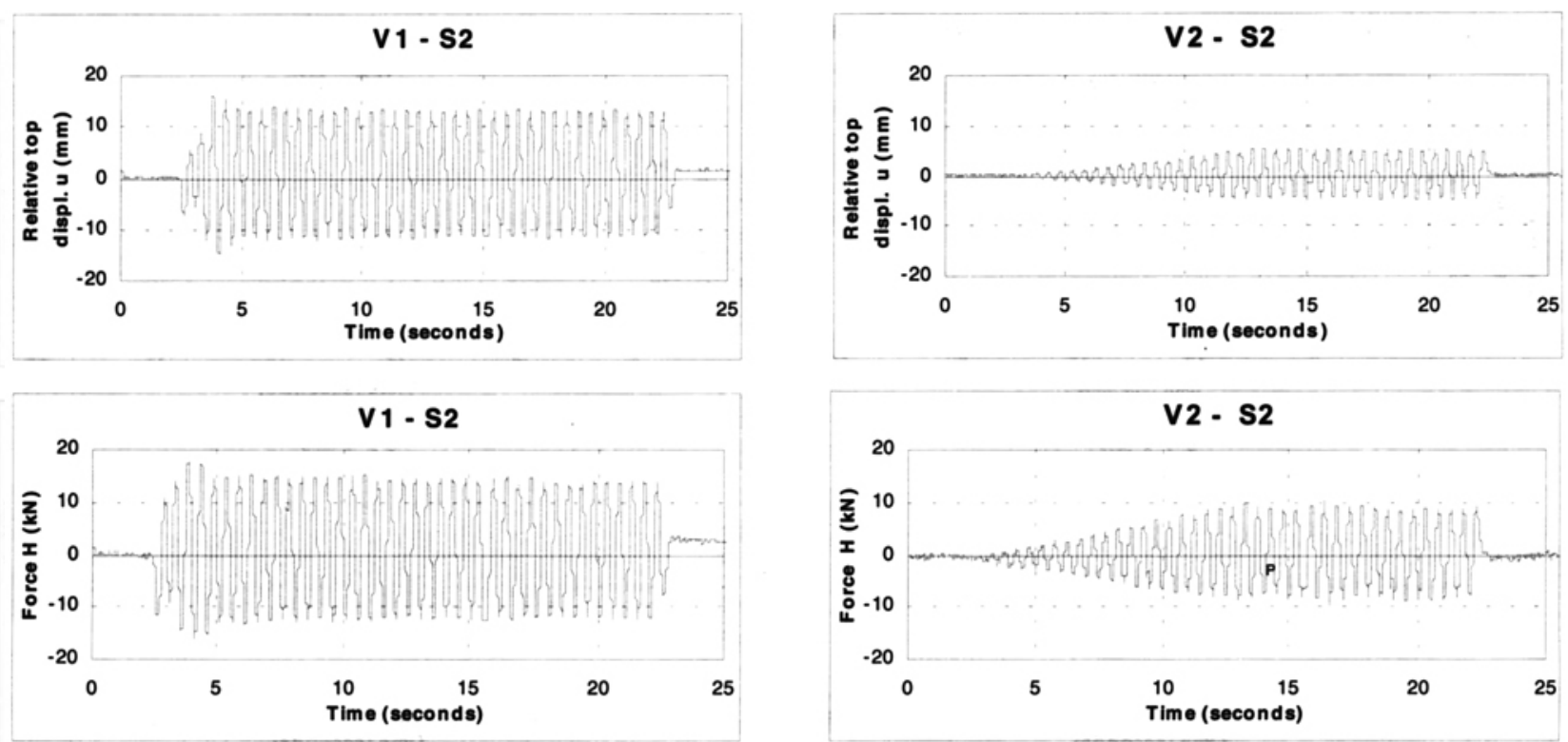

Fig 4. Variation of displacement $u$ ant load $H$ in the stage S2

The horizontal force $H(t)$ was measured directly during the experiment, while the transverse displacement $u(t)$ of the specimen was obtained indirectly through different transverse displacements measured by transducers $\mathrm{dl}, \mathrm{d} 1 \mathrm{l}$ and $\mathrm{d} 13$ [20].

In order to cover a larger range of real loading, the input signal $u_{t a b}(t)$ - controlled displacement of the shaking table - was designed differently for each specimen. It produces adequately different displacement $u(t)$ and loading $H(t)$ histories. The variation of the global variables $u(t)$ and $H(t)$ during the experiment for both V1 and V2 specimens during all of the stages S1 and S6 are presented in Figs 3-8.
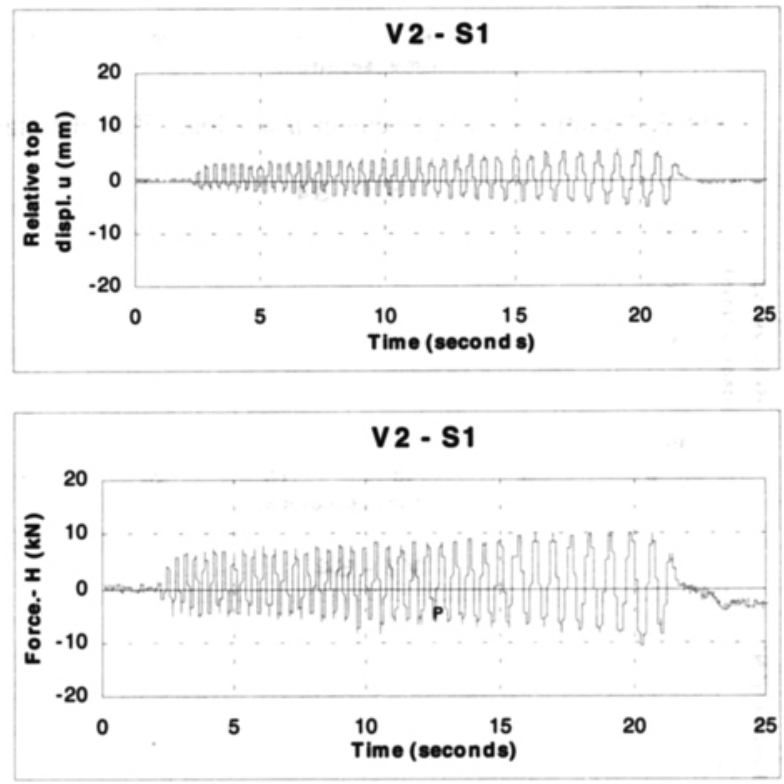

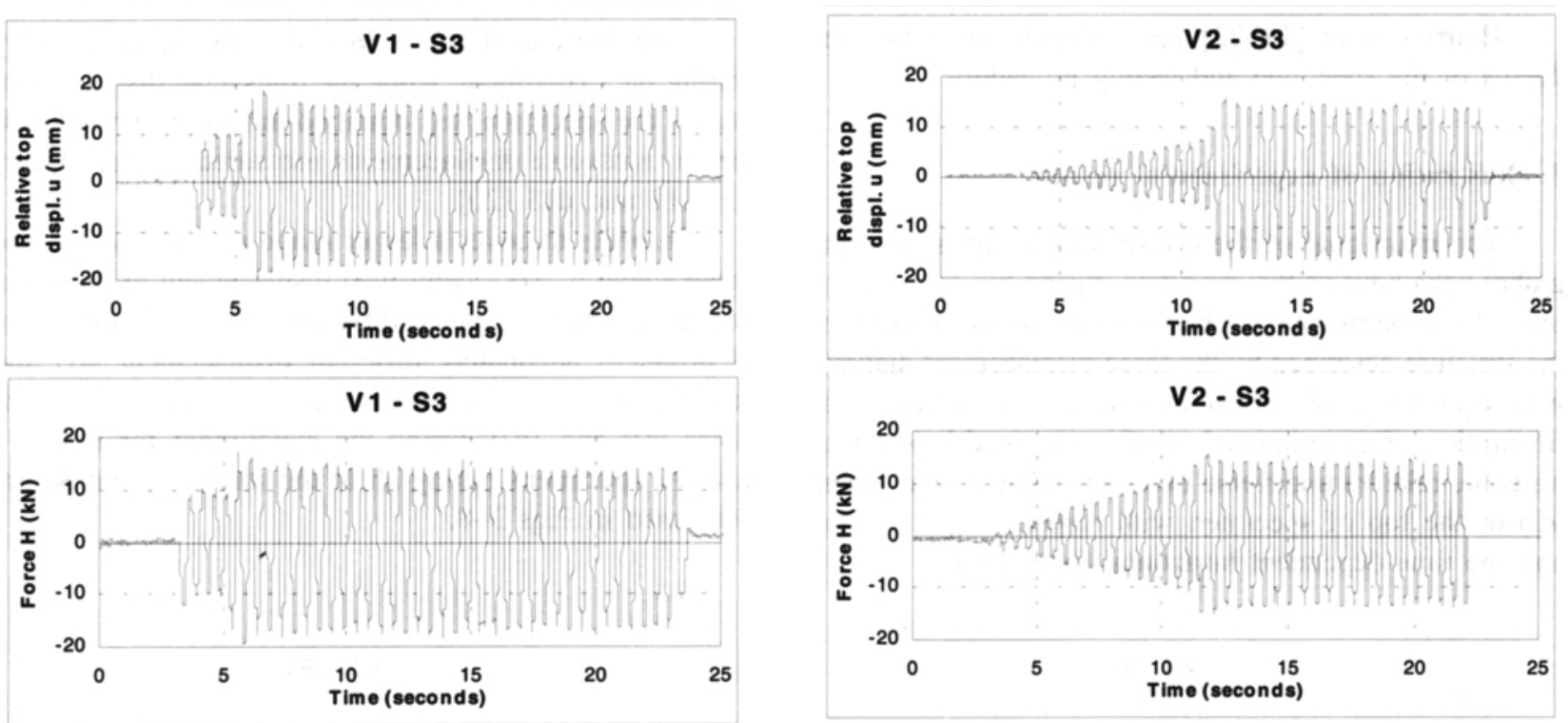

Fig 5. Variation of displacement $u$ ant load $H$ in the stage $\mathrm{S} 3$
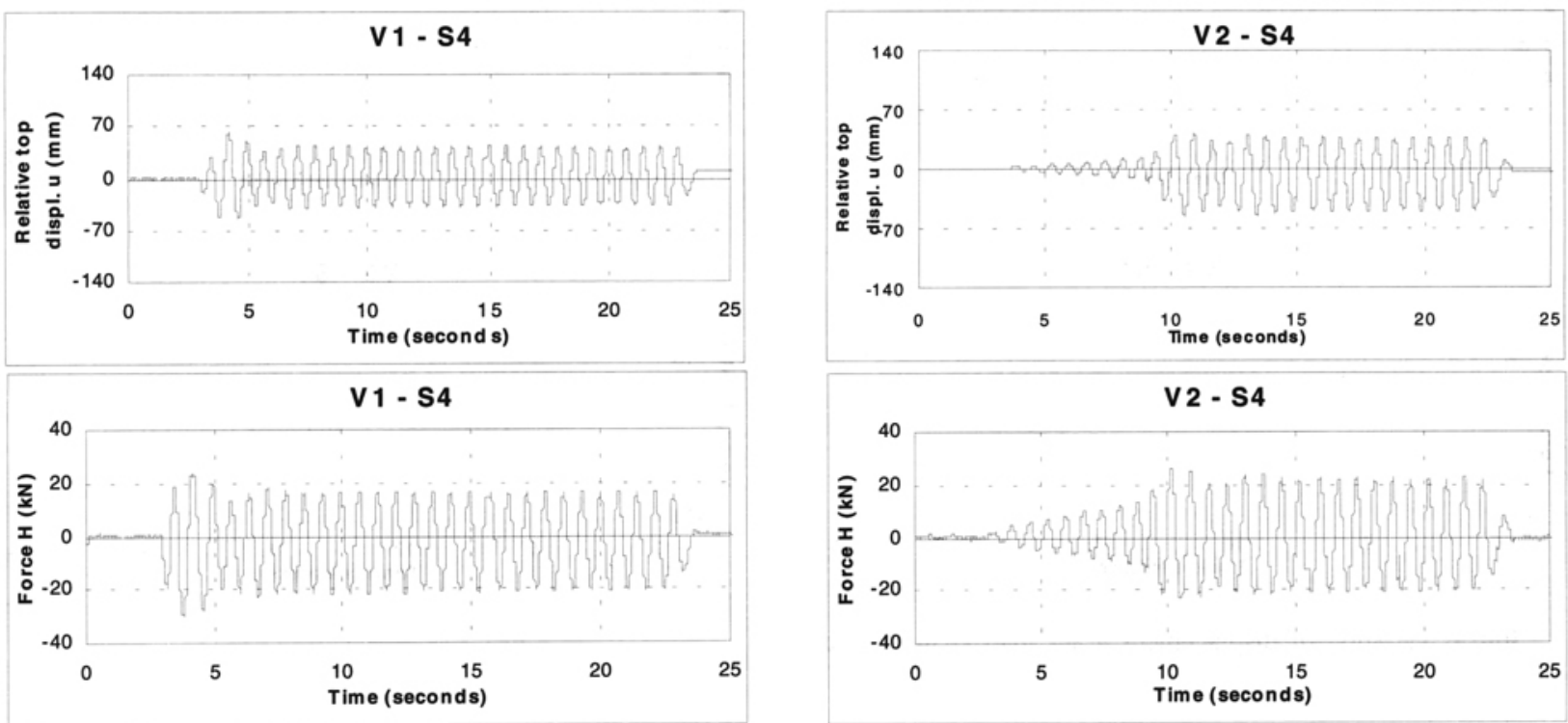

Fig 6. Variation of displacement $u$ ant load $H$ in the stage S4
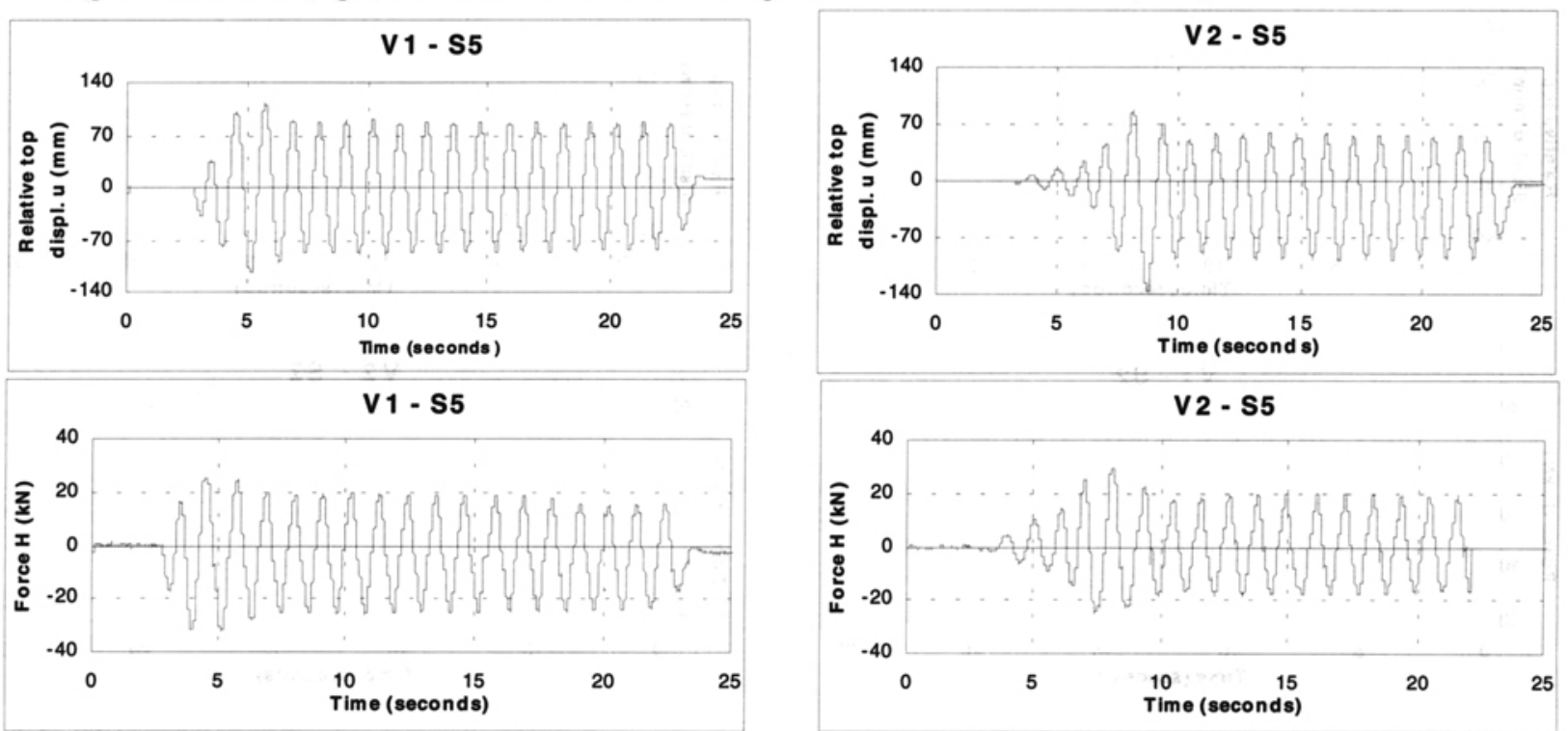

Fig 7. Variation of displacement $u$ ant load $H$ in the stage S5 

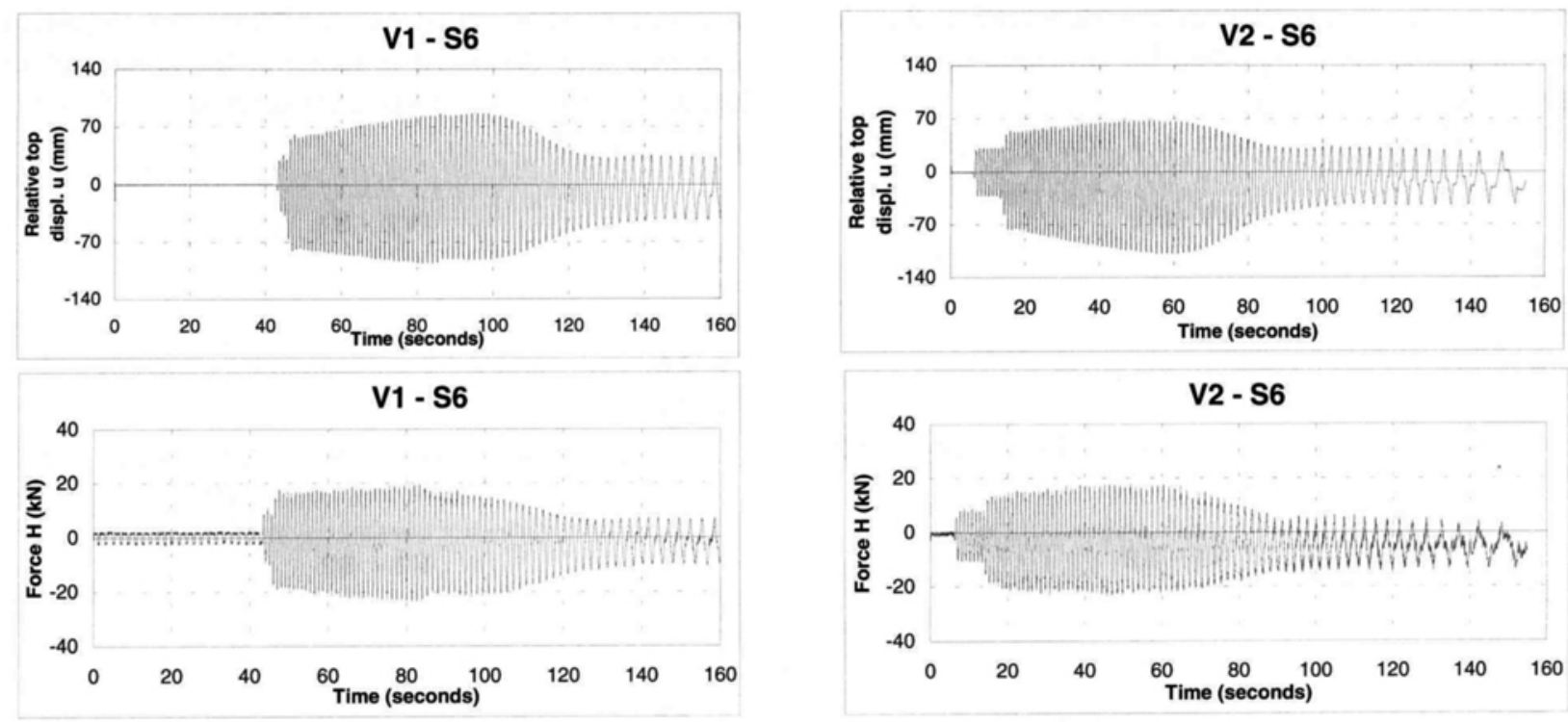

Fig 8. Variation of displacement $u$ ant load $H$ in the stage S6

For the specimen V1, during the whole active interval (between 2,5 and $22,5 \mathrm{sec}$ ) the controlled displacement of the shaking table $-u_{t a b}(t)$ - was designed as a sine wave with constant amplitude and has generally reproduced the response of the structure (global force and displacement) as a stable sine wave motion. This means that the mass of the structure $m$ was active in the starting phase.

For the specimen V2 the controlled displacement of the shaking table $-u_{t a b}(t)$ - was designed as a sine wave having a progressively increasing amplitude during the first phase (interval between 2,5 and 12,5 sec) and constant amplitude during the second phase (interval between 12,5 and $22,5 \mathrm{sec}$ ). During the first 9 seconds the external mass $m$ acted actually as a dead mass and the top displacement $u(t)$ remained almost zero while during the second phase of motion it has produced increasing amplitudes.

In order to observe a failure at the final stage S6, the experiment was then performed in another manner. Here, the controlled displacement of the shaking table $u_{t a b}(t)$ - was designed, for both specimens, as a sinesweep signal having a progressively decreasing frequency. After 16 seconds of loading inertia effect produces increasing displacement amplitudes. During the first 70 seconds of loading, the inertia effect produced increasing load and displacement amplitudes while the column was still able to resist the external load. After a critical accumulation of local damages, the total crushing was observed with corresponding decreases of the load and displacement amplitudes.

The force-displacement diagrams $H-u$, presented for all loading stages in Fig 9 finally illustrate the global behaviour of the specimen. Here, all diagrams are drawn in a unique scale in order to allow the reader to follow easily the changing of the column stiffness caused by the damage progression during the entire loading history.
In spite of a different character of loading, damage of both specimens has occurred in a similar way.

\section{Investigation of evolution of the global damage}

The current shaking table testing of high-strength reinforced concrete columns under horizontal and vertical loading covers a wide range of column behaviour including evolution of damage and failure phase. The accumulation of damage in reinforced concrete structures is a process developing during the whole period of operation until a critical state (failure) of the structure is reached. The failure phase is characterised by the development of large through-cracks and a final crushing of the concrete at the base of the columns, near the footing connection. An exact evaluation of the interaction between both phases is a rather complicated task. Actually, it was verified that failure already started at stage S5, but, for sake of simplicity, it was assumed that the failure phase covered only the loading stage S6. Finally, the investigation of evolution of damage was focused between the loading stages S1 and S5.

The quantitative investigation of damage is mainly associated with the local approach used in continuum damage mechanics assuming that it is possible to establish an evolution law of a set of damage parameters at each point of the structure. This approach is feasible for homogeneous materials but it has serious drawbacks when in the presence of non-homogeneous materials or for investigation of the macroscopic behaviour of reinforced concrete structures. When evaluating the damage of an entire structure, especially in the case of experimental investigations, the global approach may be used. The global damage may be caused not only by the material properties but also by the geometry and construction of the entire structure, non-homogeneity of materials, loading history, different manufacturing imperfections, etc. 
Therefore due to complex nature investigation the global damage is more important for structural engineering as the local one.

Considering the column as a structure with a single
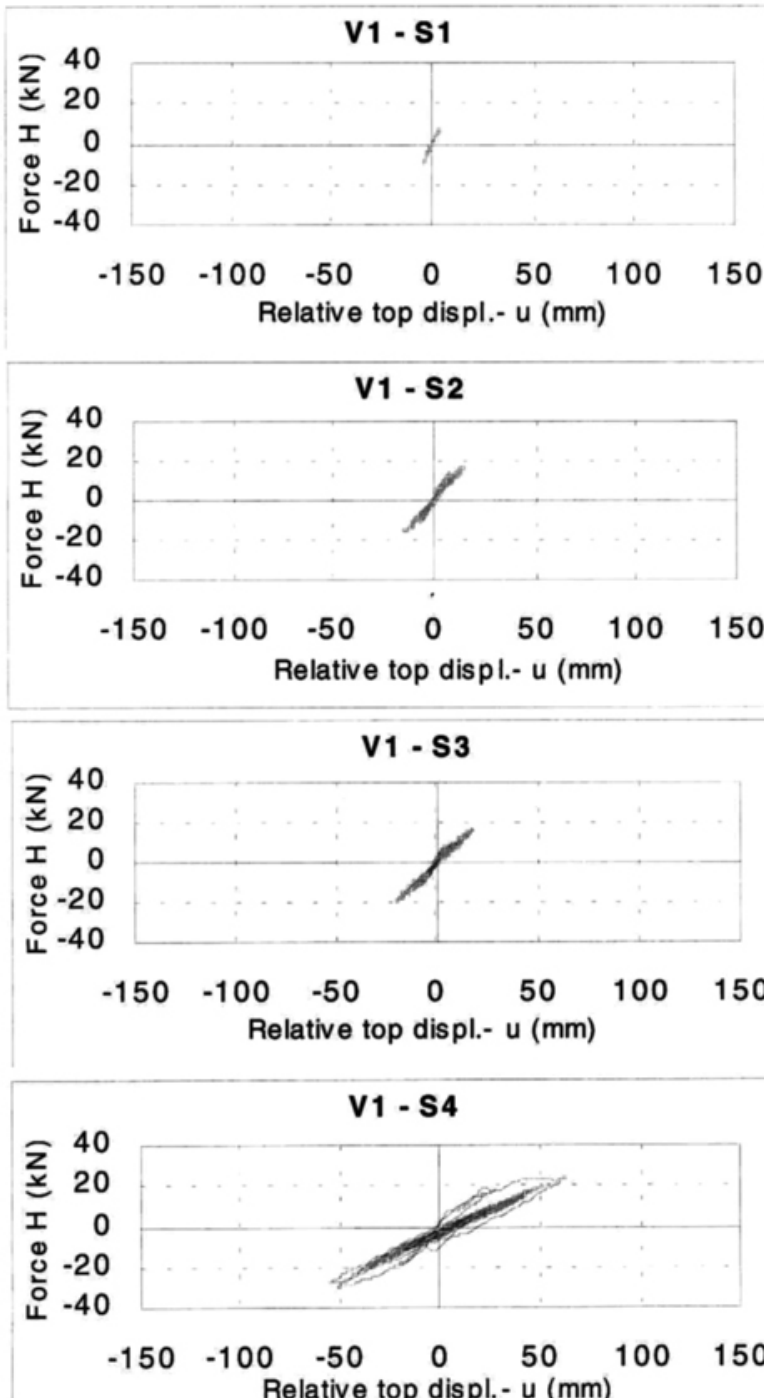

Relative top displ. - u (mm)
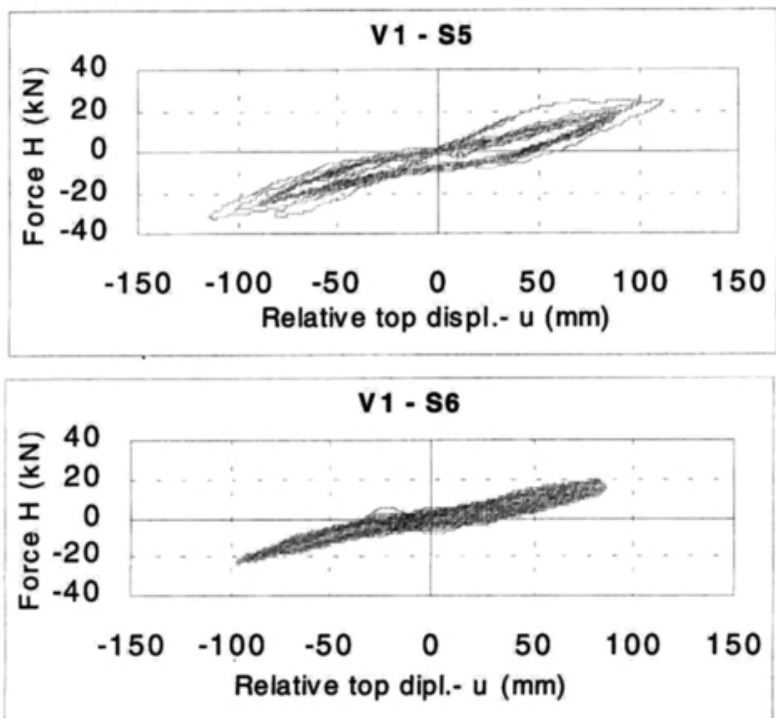

Fig 9. The global force-displacement diagrams degree of freedom, its global non-linear time-dependent behaviour may described in terms of the horizontal top displacement $u(t)$ and force $H(t)$ diagrams as it is presented in Fig 9.
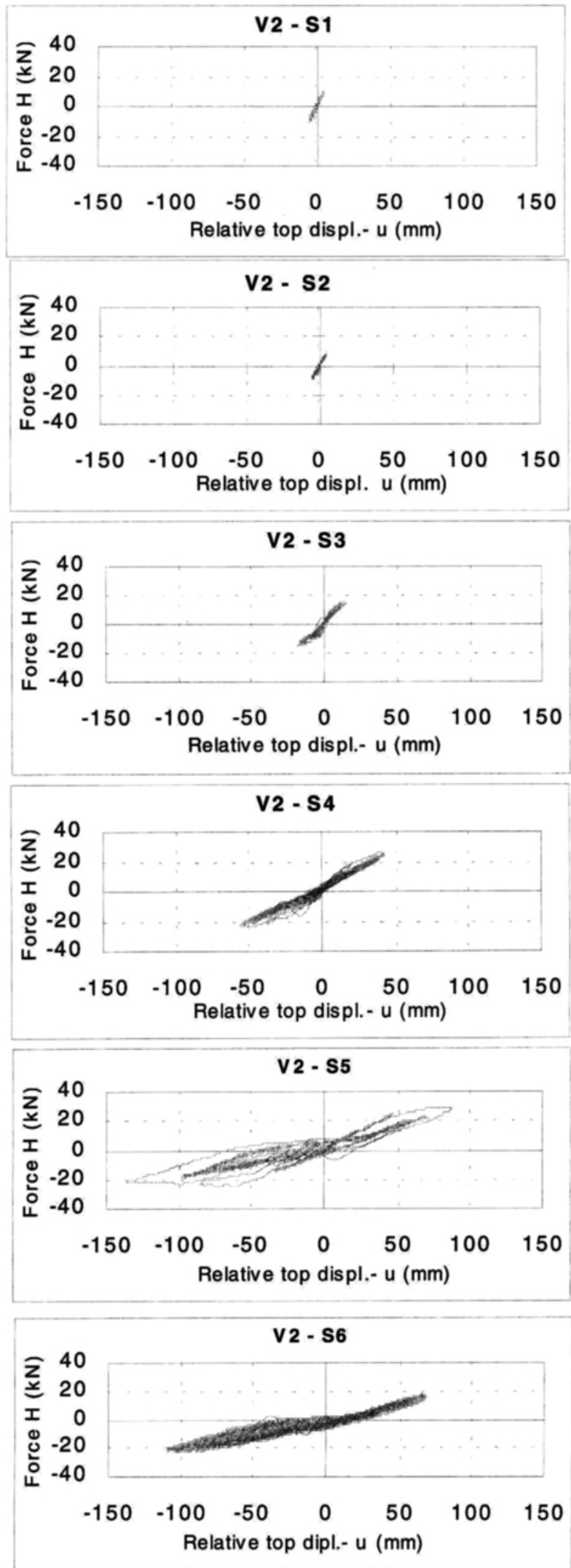

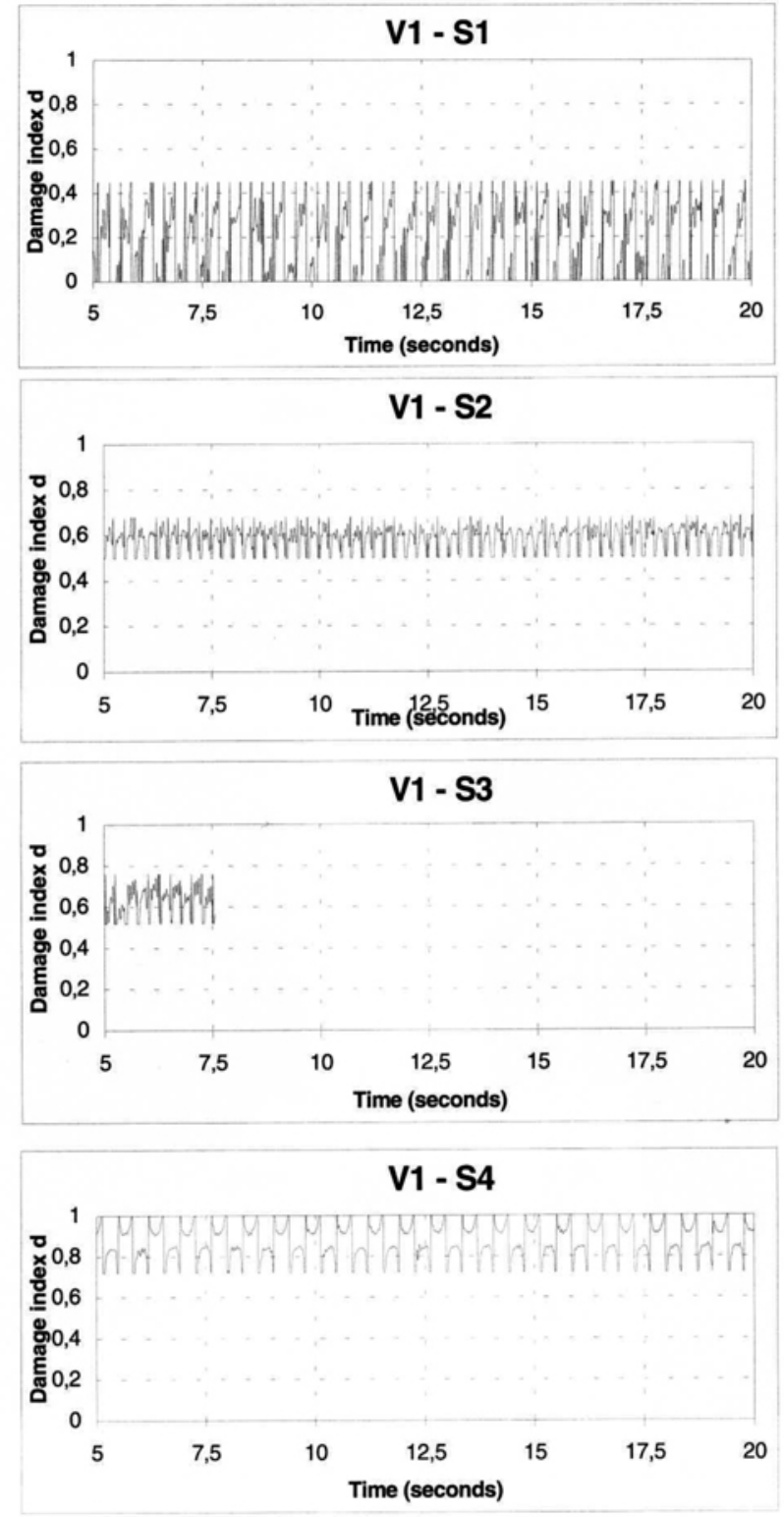

V1 - S5

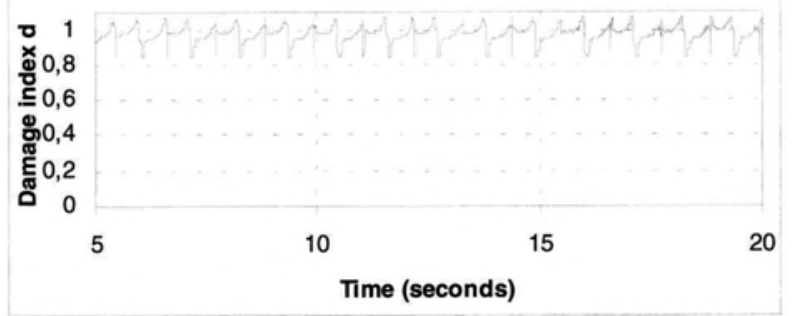

Fig 10. Variation of damage index

By applying the definitions used in continuum damage mechanics, the global bending stiffness $K(u, t)$ may be considered as an effective stiffness, which decreasing results basically from the increasing of a global damage index $d(t)$ :

$$
K(t)=K_{o}(1-d(t)) .
$$

Here, the scalar variable $d(t)(0 \leq d(t) \leq 1)$ represents the reduction of the global stiffness $K(t)\left(K_{o} \geq K(t) \geq K_{\text {min }}\right)$
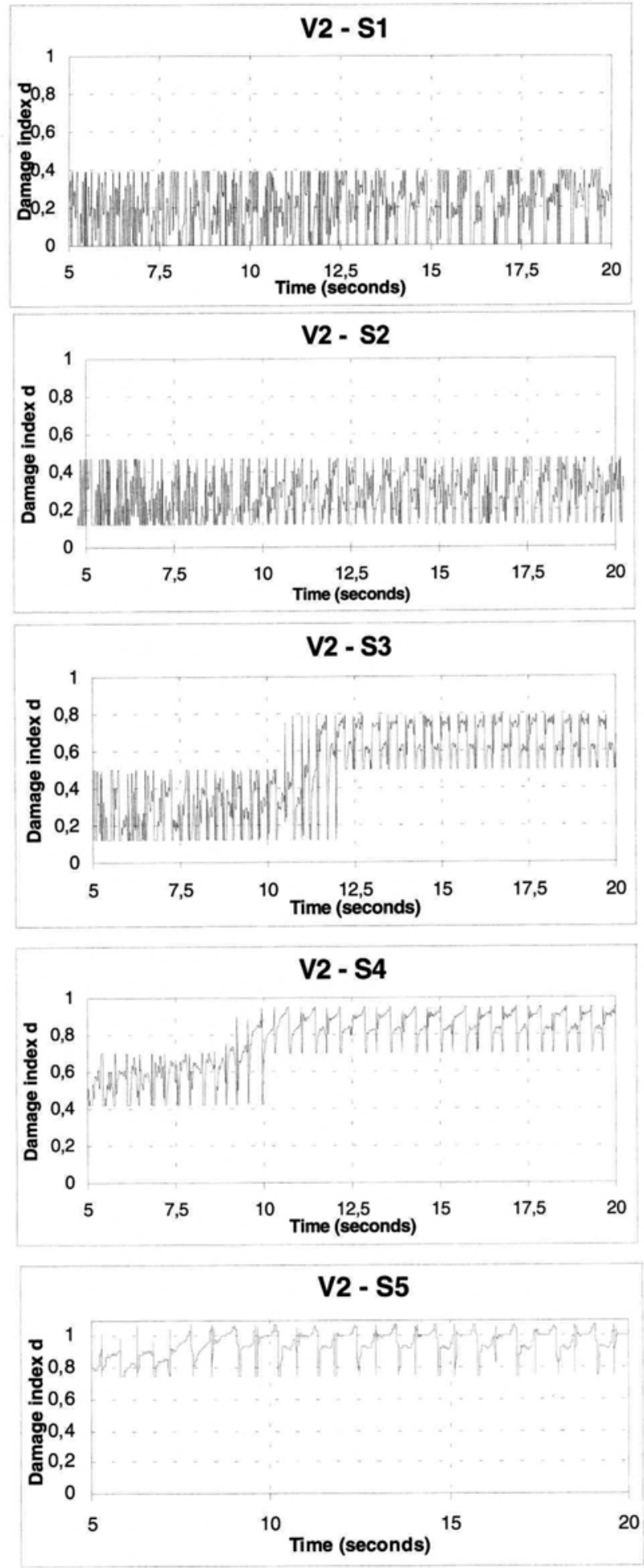

compared to the stiffness value $K_{o}$ at the virgin state of the structure. The damage index, being defined in the usual manner as:

$$
d(t)=\frac{K_{o}-K(t)}{K_{o}-K_{\min }} .
$$

The effective global stiffness $K(t)$ may be obtained as the tangent of the loading curve:

$$
K(t)=|H(t)||u(t)| \text {. }
$$


Following the experimental results, evolution of the global damage until failure may be divided, conditionally, into three phases - a microcracking phase, a macrocracking phase and a failure phase. The first phase is limited by the development of microcracks, when the tension stresses in concrete are beyond the tension resistance. This phase corresponds to the loading stages $S 1$ and $S 2$. The macrocracking phase is characterised by the occurrence of macrocracks and the changes in their length and width. This final phase started at the end of the second loading stage $\mathrm{S} 2$.

The variation of the damage index $d$, presented in Fig 10, clearly illustrates the behaviour of the specimens observed during testing. At the stage $\mathrm{Sl}$, both specimens V1 and V2 were subjected to low values of horizontal force amplitude $\left(H_{\max }=8 \mathrm{kN}\right)$ and their behaviour was purely elastic with no evidence of macrocracking. At this loading level it was expected to test just the virgin state of the specimens but it has been observed the occurrence of damage. The global damage was caused by local damage effects of different origin (due to disregard of the technological requirements of manufacture and testing set-up, local microcracking, crushing, etc) and the damage index reached the value $d=0,3$. This kind of damage has resulted in a slightly different ratio of damage for each of the specimens and a final non-symmetric behaviour. The specimen V1 was mainly affected by a one-sided local damage and has provided a difference $\Delta d=0,3$ when comparing both sides bending. The same loading level has been achieved for the specimen V2 at stage $\mathrm{S} 2$ and a similar status of damage was reached.

At the stage S2, the occurrence of two microcracks was observed in both specimens. At the stages S3 and S4 a dominant macrocracking was responsible for the progression of damage and its index has reached the critical value $d=0,8$. The accumulation of damage, in the case of the specimen V1, under a strongly impulsive loading was related to higher load values at the beginning of each loading phase during a short period between 3 and 5 seconds. For the specimen V2, with a permanent increase of the loading amplitude, the damage accumulation period lasted between seconds 3 and 12. The damage diagrams illustrate the opening of macrocracks between the seconds 11 and 12, at stage S3, and between seconds 6 and 10, at stage $S 4$. The damage became stable during stage S5. At the final stage S5 both sides of both specimens were damaged almost symmetrically.

In spite of their similarities the differences in behaviour of each specimen have been pointed out. The almost constant loading amplitude used in the case of specimen Vl has caused a damage progression directly related to the loading level but did not provide any evidence of damage accumulation during cycling. On the contrary, the behaviour of specimen V2 has illustrated a cyclic damage accumulation that was most probably caused by the permanently increasing of the loading amplitude.

A view of each specimen after failure is presented in Fig 11.
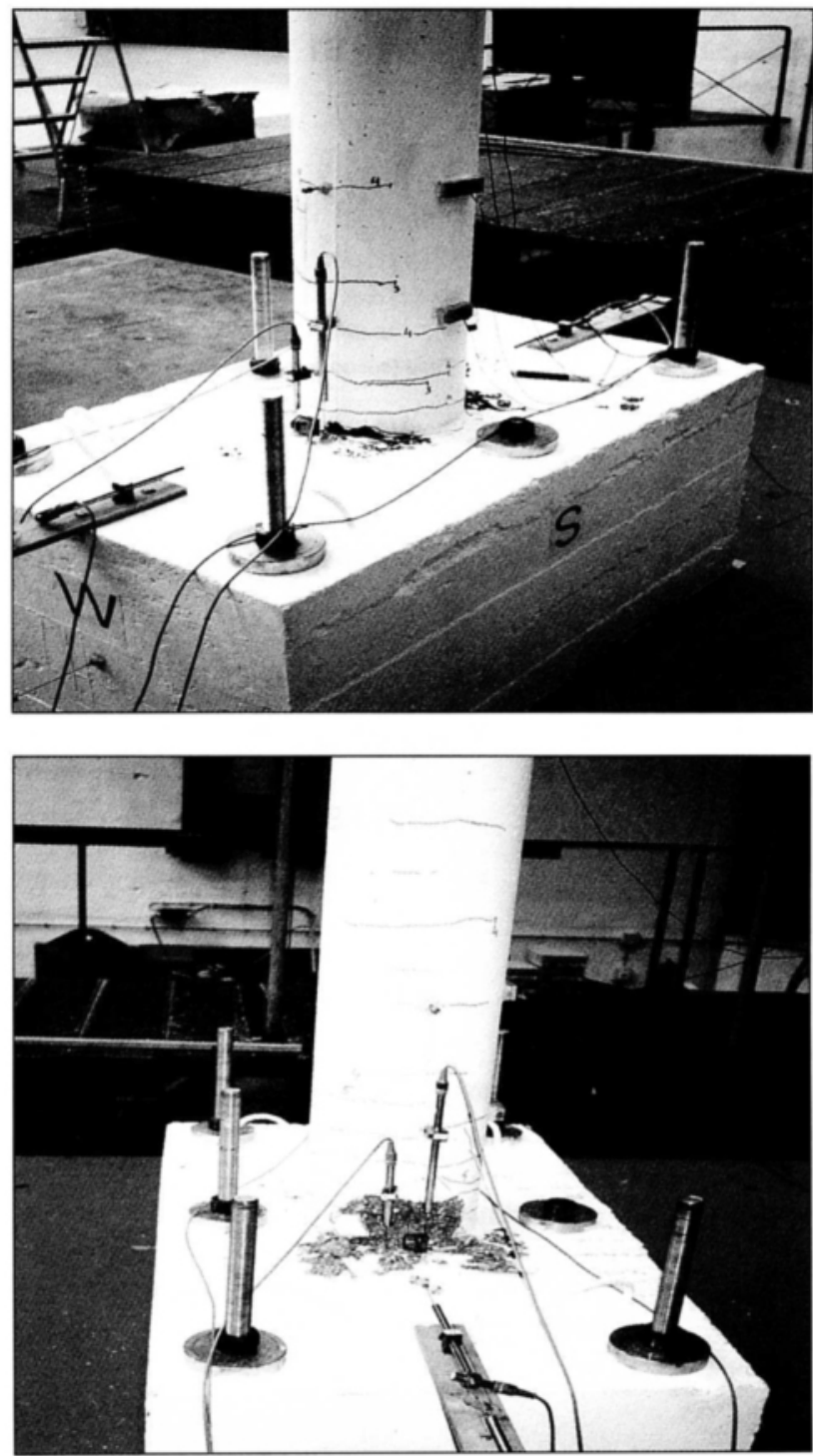

Fig 11. View of support zones of specimens V1 and V2 after stage S5

\section{Conclusions}

On the basis of a shaking table investigation of global damage of high-strength reinforced concrete columns under horizontal and vertical loading, the following conclusions may be drawn:

1) The specimens under investigation were designed and reinforced in a way that the evolution of damage was predicted by dominated deformations, cracking and crushing of the concrete.

2) At the initial phase $(d \leq 0,4)$ the global damage was caused by local damage effects of different origin (due to the disregard of technological requirements of manufacture, local microcracking, crushing, etc). This kind of damage showed a non-symmetric behaviour and slightly different ratios of progression for each of the specimens. The higher-level damage $(d \geq 0,4)$ was caused by macrocracks opening in the specimens and by the disconnection of the specimens and their footings. 
3) The increasing of loading values was a dominating factor of global damage. This was verified by variation observed in the damage index. Accumulation of damage, for specimen V1, with a strongly impulsive loading, was related to higher load values at the beginning of each loading phase, in the short period between seconds 3 and 5 . For the specimen V2, with permanently increasing loading amplitude, the damage accumulation period lasted between seconds 3 and 12 . A value of about $50 \%$ of damage was reached during the opening of macrocracks at the end of the loading increase phase. The accumulation of damage for the successive loading cycles has remained insignificant, most probably due to the relatively small number of cycles imposed.

4) The experimental results obtained will be used for modelling and design of reinforced high-strength concrete columns as well as for a better understanding of the properties of this type of concrete.

\section{Acknowledgements}

The studies described in this paper were partially funded by the European Community Program "Access to Large Scale Facilities - The Large Installations Plan", in the framework of ECOEST, "European Consortium of Earthquake Shaking Tables", contract ERBCHGECT 920010, supplementary agreement ERBCIPDCT 940089, PECO, for the support to scientists from Central and Eastern European Countries.

Armol-Freyssinet S.A. has supplied and applied the prestressing free of charge.

\section{References}

1. Kachanov, L. M. On the creep fracture time. $l z v . A N S S S R$ (Известия АН СССР), 8, 1958, p. 26-31 (in Russian).

2. Lemaitre, J. and Lipman, H. Course of damage mechanics. Springer, New-York, 1996. 232 p.

3. Suanno, R. and Ramm, E. Analysis of three-dimensional reinforced concrete structures with coupling of plasticity and damage theories. In: Z. P. Bažant (ed.), etc., Fracture and damage in quasibrittle structures, E\&FN Spon, London, 1994, p. 519-532.

4. Papa, E. and Taliercio, A. Anisotropic damage model for the multiaxial static and fatigue behaviour of plain concrete. Engng. Fracture Mech., 55, 2, 1996, p. 163-179.

5. Khan, A. R.; Al-Gadib, A. H. and Baluch, M. H. An elasto damage constitutive model for high-strength concrete. In: $R$. de Borst (ed.), etc., Computational modelling of concrete structures, Vol 1, Balkema, Roterdam, 1998, p. 133-142.

6. Priestley, M. J. N. and Park, R. Strength and ductility of concrete bridge columns under seismic loading. ACI structural journal, 84 (1), 1987, p. 61-76.

7. Barr, B. L. G.; Abusaif, H. F. and Gorst, N. J. S. The application of the stiffness damage test. In: Z. P. Bažant (ed.), etc., Fracture and damage in quasibrittle structures, E\&FN Spon, London, 1994, p. 427-432.

8. Panagiotakos, T. B. and Fardis, M. N. Deformation of reinforced concrete members at yielding at ultimate. $A C I$ structural journal, 98 (2), 2001, p. 135-148.

9. Paultre, P.; Legeron, F. and Mongeau, D. Influence of concrete strength and transverse reinforcement yield strength on behaviour of high-strength concrete columns. $A C I$ structural journal, 98 (4), 2001, p. 490-501.

10. Dong, Z. and Keru, W. Fracture properties of high-strength concrete. Journal of materials in civil engineering, 13 (1), 2001, p. 86-88.

11. Foster, S. J. On behavior of high-strength concrete columns: Cover spalling, steel fibers, and ductility. $A C I$ structural journal, 98 (4), 2001, p. 583-589.

12. Witmann, F. H. Fracture Mechanics and durability of high performance concrete. $C D$ World congress in fracture mechanics, Oral/poster ref.: 10010590R.

13. Crewe, A. J. and Severn, R. T. The European collaborative programme on evaluating the performance of shaking tables. Philosophical transactions of the royal society of London. Series A - Mathematical, physical and engineering sciences, 59 (1786), 2001, p. 1671-1696.

14. Conte, J. P. and Trombetti, T. L. Linear dynamic modelling of a uniaxial servo-hydraulic shaking table system. Earthquake engineering \& Structural dynamics, 29 (9), 2000, p. 1375-1404.

15. Ogawa, N.; Ohtani, K.; Katayama, T. and Shibata, H. Construction of a three-dimensional, large-scale shaking table and development of core technology. Philosophical transactions of the royal society of London. Series A - Mathematical, physical and engineering sciences, 359 (1786), 2001, p. 1725-1751.

16. Emílio, F. T.; Duarte, R. T.; Carvalhal, F. J.; Costa, C. O.; Vaz, C. T. and Corréa, M. R. The new LNEC shaking table for earthquake resistance testing. Document LNEC757, 1989.

17. Duarte, R. T. Development of shaking table testing techniques. In: Report of Working Group 11, 10th European Conference on Earthquake Engineering, Vienna, Austria, August/September 1994, Vol 4, p. 3135-3144.

18. Carvalho, E. C. Seismic testing of structures. In: IIth European Conference on Earthquake Engineering, Paris, France, September 1998.

19. Bairrăo, R.; Vaz, C. T. and Duque, J. Dynamic tests on high-strength reinforced concrete columns under combined vertical and horizontal loading. Report LNEC/C3ES/SES236/98.

20. Bairrăo, R.; Kačianauskas, R. and Kliukas, R. Experimental investigation on $\mathrm{RC}$ columns under horizontal and vertical loading using shaking table tests. Civil Engineering, Vol 4, 4, 1998, p. 244-251.

21. Bairrăo, R.; Vaz, C. T.; Kačianauskas, R. and Kliukas, R. Shaking Table Tests of Reinforced Concrete Columns under Horizontal and Vertical Loading. In: Transactions of the 15th International Conference on Structural Mechanics in Reactor Technology (SmiRT-15), Seoul, Korea, August 15-20, 1999, p. VI-155-VI-162.

22. Bairrăo, R.; Vaz, C. T.; Duque, J.; Kačianauskas, R. and Kliukas, R. Shaking Table Tests of High-Strength Reinforced Concrete Columns under Horizontal and Vertical Loading (submitted to Nuclear Engineering and Design). 